\title{
A ESCRITA ACADÊMICA EM FOCO: PROCESSOS DE RETEXTUALIZAÇÃO EM MONOGRAFIAS DE CIÊNCIAS SOCIAIS E LETRAS ${ }^{1}$
}

\author{
Clara Regina Rodrigues de Souza* \\ Williany Miranda da Silva**
}

\begin{abstract}
Resumo: O presente trabalho se situa na discussão sobre escrita acadêmica e investiga processos de retextualização no gênero monografia. Parte-se da observação de que este gênero é validado oficialmente pelo seu poder institucional de autorizar a conclusão de cursos de graduação e especialização, além de que é escrito a partir de questões de pesquisa postas em sua introdução e retomadas no decorrer de seu texto. Buscou-se responder: de que maneira processos de retextualização validam a produção escrita de monografias? No intuito de resposta, analisam-se seis exemplares do gênero, dos Cursos de Licenciatura Plena em Letras e de Bacharelado em Ciências Sociais. Os resultados obtidos atentam para a identificação de processos de retextualização internos, de adaptação, reformulação e argumentação, mobilizados na seção-alvo, análise de dados.
\end{abstract}

Palavras-chave: Escrita Acadêmica. Gênero Monografia. Retextualização.

\begin{abstract}
This paper discusses academic writing and investigates retextualization processes in the monograph genre. The work considers the notions that a) this genre is validated by its institutional power to authorize the conclusion of Undergraduate and Specialization Courses and b) it is written from research questions put in the introduction and resumed throughout the text. Thus, it sought to answer the question: How do retextualization processes validate the written production of monographs? Therefore, it examined six cases of this genre, resultant from the Degrees in Letras and in Social Sciences. The results obtained point to the identification of internal retextualization processes of adaptation, recasting and argumentation, all of them mobilized in the target section data analysis.
\end{abstract}

Keywords: Academic Writing. Monograph. Retextualization.

\section{Considerações iniciais}

A produção textual na academia tem o caráter científico de se pautar no já dito, por se constituir a partir de textos-fonte variados, como as teorias que o fundamentam e os diferentes gêneros precedentes. Das várias situações de escrita desse contexto, apreende-se como objeto de investigação o processo de retextualização interna no gênero monografia, em que questões de pesquisa são anunciadas na sua introdução e retomadas no decorrer de sua escrita, tanto no relato do percurso metodológico adotado, na análise do objeto investigado, questionado e categorizado, quanto no texto de conclusão.

Considerando tais especificidades do gênero em foco, busca-se responder: de que maneira processos de retextualização validam a produção de monografias? No intuito de resposta, objetiva-se, de maneira geral: verificar estes processos como imprescindíveis à

\footnotetext{
${ }^{1}$ O presente artigo resulta da pesquisa de Mestrado, concluída em 2014, sobre retextualização na escrita de monografias, pelo Programa de Pós-Graduação em Linguagem em Ensino, da Universidade Federal de Campina Grande. A pesquisa orientada pela Prof. ${ }^{a}$ Dr. ${ }^{a}$ Williany Miranda da Silva culminou do projeto investigativo As estratégias textuais e discursivas nos gêneros orais e escritos: da sala de aula ao ambiente virtual. Versões preliminares do trabalho foram apresentadas e premiadas nos $I V$ e $V$ Gêneros na Linguística e na Literatura, respectivamente em 2013 e 2014, na Universidade Federal de Pernambuco.

* Doutoranda em Linguística pelo Programa de Pós-Graduação em Letras, da UFPE. Endereço eletrônico: clararegina.r.s@gmail.com

** Professora associada II da Unidade Acadêmica de Letras e do Programa de Pós-Graduação em Linguagem e Ensino da UFCG. Endereço eletrônico: williany.miranda@gmail.com
} 
constituição do gênero em foco. De maneira específica: interpretar a manifestação desses processos na "seção de análise de dados", parte constitutiva desse gênero. Dentre os pressupostos teóricos norteadores, consideram-se os de gênero como ação sociorretórica, com Swales $(1990$; 2004) e Bhatia (2004), e de retextualização como a transposição de uma modalidade textual escrita em outra também escrita, a partir de Marcuschi ([2001] 2010) e Matencio (2002; 2003; 2004).

Conforme discutido nas pesquisas sobre escrita acadêmica lideradas por esta autora, o contínuo estabelecido entre os textos na academia reflete o fenômeno da retextualização e sua potencialidade de realizar o saber-fazer científico. Pesquisas como estas têm em comum a constatação de que são mais mobilizados procedimentos de retextualização de expor e descrever do que de apreciar, fato que revela a necessidade de mais investigações que possam contribuir para a escrita acadêmica capaz de produzir e divulgar conhecimento científico.

Com base nessas pesquisas, investiga-se a retextualização na análise de dados de monografias. Adotou-se metodologia de cunho descritivo-interpretativista e de abordagem qualitativa na análise de monografias, recolhidas através de três critérios de coleta de dados. O primeiro critério considerou monografias de sujeitos egressos do Programa Institucional de Bolsas de Iniciação Científica (PIBIC), que tivessem sido orientadas por professores distintos, por causa da referência do programa ${ }^{2}$ de iniciar graduandos em práticas acadêmicocientíficas, contribuindo na formação de bolsistas para o desenvolvimento de pesquisa, através de parceria entre Instituição de Ensino Superior (IES), orientador e bolsista.

O segundo selecionou monografias de cursos, do Centro de Humanidades, da UFCG, avaliados como satisfatórios pelo Exame Nacional de Desempenho de Estudantes (Enade); foi estabelecido pela necessidade de delimitar o corpus de análise, sem perder de vista a credibilidade de monografias pertencentes a um contexto privilegiado de produção: no caso do PIBIC, pelo suporte institucional de pesquisa científica; no caso do Enade, pela indicação da qualidade de cursos de graduação, haja vista ser um instrumento de avaliação trienal que conceitua, na escala de 1 a 5 , o desempenho de ingressantes e concluintes de graduações, por meio de uma prova de formação geral e específica ${ }^{3}$.

O terceiro critério delimitou para as monografias defendidas no triênio 2009-2011, por ser o período cíclico de avaliação corresponde à última divulgação do exame, em 2011, ao tomar como referência o ano de início da presente pesquisa, 2012. Com base nesses critérios, foram selecionadas seis monografias de sujeitos que concluíram a graduação no triênio supracitado, de cursos que obtiveram conceituação satisfatória no exame: 1) o de Bacharelado em Ciências Sociais, com conceito máximo 5; e 2) o de Licenciatura Plena em Letras em Língua Portuguesa, com conceito 4, próximo ao nível máximo de pontuação. Particularmente, no caso das monografias de Letras, interessaram as da Área da Linguística, por ser o próprio contexto de pertencimento da presente pesquisa. Por conseguinte, foram coletadas, a partir da Coordenação dos respectivos cursos, três monografias de Ciências Sociais, defendidas em 2011, e três de Letras, defendidas em 2011, 2010 e 2009, respectivamente.

As monografias recolhidas revelam particularidades de produção de cada curso. As três de Letras interessam por investigar temáticas linguísticas em relação à formação do professor. Em ML-1 ${ }^{4}$, a interferência das unidades retóricas na prática de seminário para a mobilização de conteúdos; em ML-2, o ensino, a avaliação e as concepções de escrita na

\footnotetext{
${ }^{2}$ Conforme disponível no portal do Conselho Nacional de Desenvolvimento Científico e Tecnológico (CNPq): http://www.cnpq.br/web/guest/pibic. Acesso em: 17 jun. 2013.

${ }^{3}$ De acordo com o portal do Instituto Nacional de Estudos e Pesquisas Educacionais Anísio Teixeira (INEP): http://portal.inep.gov.br/indice-geral-de-cursos. Acesso em: 27 maio 2013.

4 Os dados coletados foram caracterizados a partir de um código alfanumérico para identificar as três monografias de Letras (ML-1, ML-2 e ML-3), bem como as três de Ciências Sociais (MCS-1, MCS-2 e MCS-3).
} 
atuação de professoras da disciplina Prática de Leitura e Produção Textual II (PLPT II); e em ML-3 a(s) perspectiva(s) teórico-metodológica(s) na formação/atuação de estudantes de Letras para a aquisição de conhecimentos sobre oralidade.

Nas monografias coletadas de Ciências Sociais, a relação entre questões e análise ilustra a descrição requerida de problemáticas sociais em contextos situados. Em MCS-1, o processamento de mudança nas estratégias produtivas do semiárido a partir da crise do sistema pecuária/algodão. Em MCS-2, a formação e atuação de Agentes de Desenvolvimento Regional Sustentável em contexto de caprinocultura. Em MCS-3, a construção das relações sociais entre os ciganos de Sousa e os de Patos.

As análises desenvolvidas nestas monografias evidenciam a produção de conhecimento esperada em seu contexto de ação. Algumas razões justificam a escolha deste gênero situado em contexto sociorretórico, isto é, entendido por sua ação social e cultural, bem como por suas estratégias textuais: 1) por evidenciar práticas de leitura/escrita apreendidas na graduação, elucidando o processo de ensino-aprendizagem do meio; 2) por ser uma produção obrigatória em vários cursos - a exemplo dos selecionados - com a responsabilidade de autorizar o recebimento do título de graduado; 3) por oficializar a permissão para a continuidade no ambiente acadêmico, em pós-graduações e, por fim, 4) por mobilizar processos de retextualização de orientações teóricas apreendidas, que fornecem subsídios para análise de dados.

Além destes motivos, monografias são escritas em um contínuo que propicia um estudo sobre retextualização ainda não contemplado na literatura, ao evidenciar uma conexão interna em que questões de pesquisa são anunciadas na introdução do gênero e retomadas tanto no relato do seu percurso metodológico adotado, quanto na sua análise do objeto investigado, questionado e categorizado. Por fim, questões são discutidas e respondidas em sua conclusão. Portanto, na conexão interna estabelecida, sua análise evidencia o fazer científico do pesquisador, através da apreciação de dados pelo confronto com teorias e com o contexto social de investigação. Para a verificação deste contínuo, seguem-se dois tópicos teórico-analíticos do processo de retextualização apreendido. Em um, os processos de adaptação, reformulação e argumentação são interpretados. No outro, o contínuo entre esses processos é discutido.

\section{Processos e estratégias de retextualização no gênero monografia}

A partir da abordagem sociorretórica, com Swales (1990; 2004) e Bhatia (2004), que considera gêneros como ação textual e social, compreende-se que monografias decorrem das práticas desenvolvidas na graduação, em situações de ensino/aprendizagem com, por exemplo, os professores e demais alunos das disciplinas cursadas e com o professor orientador do trabalho. Com base nessa compreensão de gênero, a análise que segue neste artigo também contribui com os estudos sobre retextualização da Linguística de Texto. As situações processuais em que textos são transformados em outros são diversas, como as várias possibilidades, amplamente discutidas por Marcuschi ([2001] 2010), de atividades em que gêneros são retextualizados da modalidade falada para a escrita, da falada para a falada, da escrita para a falada e da escrita para a escrita.

Dentre essa diversidade de contínuo textual, mas também, social e cultural, monografias são escritas em um processo de retextualização a partir de textos-fonte (TF) variados, como os textos teóricos utilizados e os diferentes gêneros que as precederam, a exemplo de esquemas, resumos, resenhas e o projeto monográfico. Ademais, na sua arquitetura textual interna, sua seção de análise é escrita na inter-relação com a de introdução. 
Isto ocorre porque há uma dependência textual-discursiva que mobiliza estratégias no contínuo entre o texto-fonte (seção de introdução) e o retextualizado (seção de análise de dados) no decorrer do mesmo gênero.

O referido processo de apropriação entre textos é complexo e realizável por meio de estratégias. Em sua tese, Silva (2013) analisa os processos de retextualização evidenciados em exposições orais de contexto acadêmico, considerando que a compreensão de fontes teóricas utilizadas e o domínio desses processos interferem significativamente na qualidade das exposições. Igualmente a pesquisadora, reconhecem-se como estratégias, neste artigo, as conceituadas operações de retextualização de Marcuschi ([2001] 2010), porque são materializadas textualmente em decorrência de processos cognitivos. Ao estudar a retextualização do texto oral para o escrito, Marcuschi (op. cit.) considera a gradação existente entre os aspectos linguísticos-textuais-discursivos e os cognitivos, em quatro processos. $\mathrm{O}$ processo de idealização, o primeiro, diz respeito às adequações para que o texto retextualizado se aproxime de um modelo linguístico ideal, através da eliminação de marcas da oralidade, da completude da pontuação e paragrafação e/ou da adaptação ao novo texto.

O processo de reformulação permite a atuação sobre o texto, por meio do acréscimo, da substituição e da reordenação de marcas linguístico-textuais e informações apreendidas pela apropriação do TF. O de adaptação compreende o tratamento dos turnos em textos orais; de modo geral, comporta citações que o linguista não explorou, por não serem corriqueiras nos dados que investigou. $\mathrm{O}$ de compreensão, menos trabalhado pelo autor, suporta operações cognitivas mais complexas (envolvendo mudanças como inferências e possíveis falseamentos), evidenciando que um texto apenas é retextualizado quando é compreendido ou se tem certa compreensão dele (cf. Marcuschi, op. cit., p. 70). Os quatro processos apresentados possibilitam a identificação das estratégias de retextualização mais recorrentes nas monografias coletadas, bem como sugere outras, conforme se identifica nas monografias recolhidas.

Desse modo, as estratégias de retextualização acontecem através de processos linguísticos-textuais-discursivos, já que se dão em um contínuo entre texto e discurso. Como ilustrado na Fig. 1, as monografias em foco mobilizam os processos de adaptação, reformulação e argumentação; bem como evidenciam, dentre os aspectos envolvidos nos processos de retextualização abordados por Marcuschi ([2001] 2010), as estratégias de adaptação e de reformulação por acréscimo e reordenação, ilustradas a seguir:

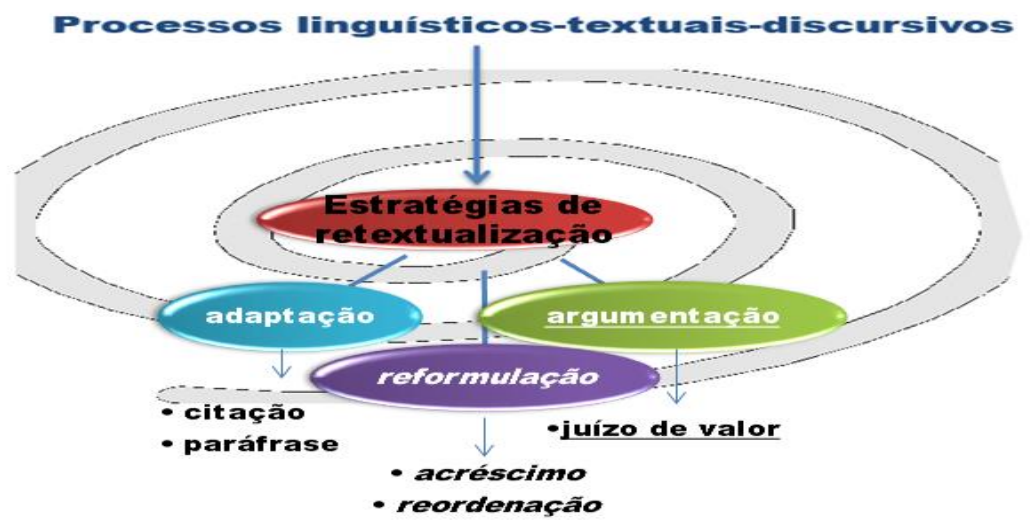

Figura 1: Estratégias de retextualização em monografias Fonte: Elaborada pelas autoras, baseada em Marcuschi ([2001] 2010) 
As primeiras estratégias apresentadas na Fig. 1 emanam da própria explicação do linguista de que a adaptação foi menos recorrente nos dados que analisou, equivalendo a estratégias que reportam a voz do outro, materializando-se via citação e paráfrase. Nada obstante, as pesquisas que temos desenvolvido (cf. Souza, 2014) comprovam a recorrência destas estratégias em gêneros acadêmicos escritos, ou seja, produzidos na/a partir da academia em situações de ensino-aprendizagem e/ou de pesquisa, como resumo, resenha e monografia, conferindo-lhes credibilidade ao trazer a sua contribuição para conhecimentos já consagrados; recorrência também ilustrada no Frag. 1:

Fragmento 1: Análise de Dados em ML-1: ACIT $^{5}$

\begin{tabular}{|c|c|c|c|}
\hline & Questão de pesquisa & Análise de Dados & \\
\hline $\begin{array}{l}1 . \\
2 . \\
3 . \\
4 . \\
5 . \\
6 .\end{array}$ & $\begin{array}{l}\text { "Qual a interferência } \\
\text { das unidades retóricas } \\
\text { na prática de seminário } \\
\text { para a mobilização dos } \\
\text { conteúdos?" } \\
\text { ML-1 }\end{array}$ & $\begin{array}{l}\text { Baseados nesse estudo, podemos acrescentar à ideia } \\
\text { apresentada por Dolz, }{ }^{6} \text { Schneuwly (et. al. op cit., p. } \\
\text { 220-221), de que "a exposição deverá ser ordenada } \\
\text { em partes e subpartes, que permitam distinguir as } \\
\text { fases sucessivas de sua construção interna", a noção } \\
\text { de didatização dos conhecimentos. } \\
\text { ML-1 (p. 56) }\end{array}$ & $\begin{array}{l}\text { Adaptação } \\
\text { (citação) }\end{array}$ \\
\hline
\end{tabular}

O Frag. 1 traz o penúltimo parágrafo de análise apresentada em ML-1, no tópico As estratégias pertinentes à unidade retórica de Fechamento. Como se percebe, a citação (linhas 2-5) é utilizada para reiterar ("podemos acrescentar à ideia apresentada por") a contribuição teórica da análise desenvolvida na monografia. A análise chega a uma importante constatação a partir de sua questão de pesquisa, ao relacionar a teoria lida aos dados e mostrar o caráter de novidade teórica descoberta de que o evento seminário funciona para mobilizar conhecimentos.

As estratégias de reformulação advêm de informações acrescidas e reordenadas na seção de análise de dados, para que a questão investigativa orientadora do gênero em foco seja respondida. Segundo Marcuschi ([2001] 2010), o acréscimo introduz informações ao TF. De acordo com Silva (2013, p. 57), esta estratégia acrescenta ao TF "uma palavra, expressão, sintagma ou enunciado". Por sua vez, conforme a discussão marcurschiana, a reordenação consiste em uma estratégia que reorienta e encadeia a argumentatividade advinda de um TF, relocando argumentos postos no fim para o início de situações textual-discursivas. Segundo o linguista, a referida estratégia foi pouco recorrente nas retextualizações de textos orais para escritos, de modo que é mais frequente em domínios mais complexos de escrita, a exemplo de artigos de pesquisa.

Ambas as estratégias foram as mais fecundas na análise das monografias em estudo, através da descrição de dados, em que a progressão textual da análise encadeia as informações acrescidas às questões de pesquisa e às apreciações realizadas e ditas de modos diferenciados, conforme se observa no Frag. 2, em que um trecho de análise de ML-3 se relaciona com a terceira questão de pesquisa apresentada em sua introdução. A questão solicita o porquê de professores tratarem o ensino da oralidade de modo assistemático. $\mathrm{O}$ trecho de análise expõe uma dessas razões identificadas, o fato de alunos já saberem falar, através da estratégia de acréscimo (nas linhas 1-4). O referido fato é posto no fim do acréscimo realizado (linha 4), sendo reordenado para o início do período seguinte, no trecho "É viável que consideremos que não compete ao professor de língua Portuguesa ensinar a falar" (linhas 4-6). Com isso, realizou-se uma troca que alterou a ordem de informações apresentadas no texto,

\footnotetext{
${ }^{5}$ Adaptação via citação (ACIT).

${ }^{6}$ Os destaques realizados no Frag. 1, e nos demais fragmentos, são de nossa responsabilidade, seguindo como base a harmonia de cores, negritos, itálicos e sublinhados da Fig. 1.
} 
evidenciando que a reordenação interdepende de outras estratégias, como o acréscimo, no seguinte fragmento:

Fragmento 2: Análise de Dados em ML-3: RA e RR ${ }^{7}$

\begin{tabular}{|c|c|c|c|}
\hline & $\begin{array}{c}\text { Introdução } \\
\text { (Questão de pesquisa) }\end{array}$ & Análise de Dados & \\
\hline 1. & 3) "Quais razões os & A prática de P3 também contraria a perspectiva de & Reformulação \\
\hline 2. & professores apontam & ensino-aprendizagem dos gêneros orais, pois está intrínseco & (acréscimo) \\
\hline 3. & para o tratamento & na afirmação da professora que oral não precisa ser & \\
\hline 4. & assistemático do ensino & ensinado porque os alunos já sabem falar. É viável que & Reformulação \\
\hline 5. & da oralidade?" & consideremos que não compete ao professor de língua & (reordenação) \\
\hline 6. & $(\mathrm{ML}-3)$ & Portuguesa ensinar a falar, mas desenvolver a competência & \\
\hline 7. & & linguística dos alunos para o reconhecimento e utilização da & \\
\hline 8. & & língua falada de acordo com as variadas situações de uso, & \\
\hline 9. & & considerando o interlocutor, o objetivo e a mensagem a ser & \\
\hline 10. & & transmitida. $\quad$ (ML-3, p. 48) & \\
\hline
\end{tabular}

Nesse processo de reformulação, a reordenação encadeia as construções textualdiscursivas tecidas, contribui para a progressão textual da análise e concatena as informações acrescidas às questões de pesquisa, às apreciações realizadas e ditas de modos diferenciados, conforme o Frag. 3:

Fragmento 3: Análise de Dados em MCS-2: RA e RR

\begin{tabular}{|c|c|c|c|}
\hline & $\begin{array}{c}\text { Introdução } \\
\text { (Questão de } \\
\text { pesquisa) }\end{array}$ & Análise de Dados & \\
\hline $\begin{array}{l}1 . \\
2 . \\
3 . \\
4 . \\
5 . \\
6 . \\
7 . \\
8 . \\
9 . \\
10 . \\
11 . \\
12 .\end{array}$ & $\begin{array}{l}\text { 2) “Qual sua [dos } \\
\text { Agentes de } \\
\text { Desenvolvimento } \\
\text { Regional } \\
\text { Sustentável] posição } \\
\text { na propagação de } \\
\text { uma ideia de } \\
\text { desenvolvimento?.” } \\
\text { (MCS-2) }\end{array}$ & $\begin{array}{l}\text { A contradição fica estabelecida quando se constata que é } \\
\text { exatamente um viés da mediação comunicativa baseada em um } \\
\text { vínculo não-reconhecido institucionalmente que é garantida à } \\
\text { adesão à caprinocultura leiteira por parte dos produtores que } \\
\text { fazem parte do grupo-alvo. Estes não sendo agentes sem } \\
\text { conhecimento sobre a atividade produtiva que praticam, tem na } \\
\text { figura do mediador ADRS uma facilidade maior para trocar } \\
\text { informações e para expor os problemas com os quais se } \\
\text { deparam ante as inovações, ou seja, com os ADRS é possivel } \\
\text { estabelecer uma relação mais próxima, comparada ao tipo de } \\
\text { relação, estabelecida com outros técnicos (como os da Emater, } \\
\text { ou de outras instituições). } \\
\text { (MCS-2, p. 53-54) }\end{array}$ & $\begin{array}{l}\text { Reformulação } \\
\text { (acréscimo) }\end{array}$ \\
\hline
\end{tabular}

O trecho apresentado na segunda coluna do Frag. 4 se encontra no último tópico, $O s$ ADRS entre diferentes saberes e racionalidades sobre a caprinocultura no cariri paraibano, de análise de MCS-2, apontando respostas para a segunda questão de pesquisa da monografia citada, conforme a primeira coluna do fragmento. A referida questão orienta uma análise que identifique a importância de mediadores compostos por Agentes de Desenvolvimento Regional Sustentável (ADRS) para o desenvolvimento de mediados, concebidos na pesquisa como os trabalhadores criadores de caprino do cariri paraibano. O trecho exposto de MCS-2 retoma a questão ao apresentar a posição social dos ADRS de ter mais poder de persuasão para com os caprinocultores e ao evidenciar a satisfatória relação comunicativa desencadeada sem reconhecimento institucional.

$\mathrm{Na}$ continuidade desse acréscimo à questão posta, utiliza-se a estratégia de reordenação (linhas 9-12), perceptível por ser encabeçada pela expressão ou seja (linha 9),

\footnotetext{
${ }^{7}$ Reformulação por acréscimo (RA) e Reformulação por reordenação (RR).
} 
reforçando a informação acrescida à medida que a reformula, como um meio de aclarar que os ADRS conseguem efetivar a comunicação com os trabalhadores, mais do que conseguem os mediadores institucionalizados, como os da Empresa de Assistência Técnica e Extensão Rural (Emater). Dessa forma, a reordenação muda o enfoque do tópico discursivo do parágrafo exposto no fragmento supracitado, o qual deixa de ser a contradição na mediação entre os ADRS e os caprinocultores, para ser os benefícios da mediação com os ADRS.

Como se percebe, a reordenação é facilmente identificável por marcas linguísticotextuais, como foi o caso de ou seja, resultando da compreensão das informações apreendidas e reformuladas. No fragmento, além dessa apropriação, a estratégia também contribuiu para o acréscimo de informações requeridas pela questão de pesquisa apresentada, tendo sido uma argumentação final sobre o papel do ADRS na mediação estabelecida.

A partir das considerações marcuschinianas, e do entendimento de que as estratégias de retextualização se relacionam ao gênero em que são mobilizadas, a argumentação via juízo de valor consolida a referida seção nas monografias coletadas, ao apreciar um objeto investigativo. De forma geral, a posição argumentativa assumida busca a resolução de questões de pesquisa sinalizadas na introdução do gênero. De maneiras diferenciadas, algumas construções revelam um posicionamento do sujeito escritor do gênero em face ao seu objeto de análise. Muitas das vezes, a utilização de determinadas palavras contribui para a realização do juízo de valor, como se aclara pelo Frag. 4:

Fragmento 4: Análise de Dados em ML-1: $\mathrm{AJV}^{8}$

\begin{tabular}{|c|c|c|c|}
\hline & $\begin{array}{c}\text { Introdução } \\
\text { (Questão de pesquisa) }\end{array}$ & Análise de Dados & \\
\hline $\begin{array}{l}1 . \\
2 . \\
3 . \\
4 . \\
5 . \\
6 . \\
7 .\end{array}$ & $\begin{array}{l}\text { "Qual a interferência das } \\
\text { unidades retóricas na } \\
\text { prática de seminário para a } \\
\text { mobilização } \\
\text { conteúdos?" } \\
\end{array}$ & $\begin{array}{l}\text { Ao determos nossa apreciação nas estratégias mais } \\
\text { recorrentes "Situar a questão", da abertura e a "Solução", } \\
\text { do fechamento, perceberemos que ambas representam } \\
\text { uma preocupação clara em atender à necessidade da } \\
\text { disciplina, pois se a pergunta é a motivadora e orientadora } \\
\text { do seminário, atingir a Solução parece ser o que define o } \\
\text { cumprimento do evento. } \\
\text { (ML-1, p. 38) }\end{array}$ & $\frac{\text { Argumentação }}{\text { (juízo de valor) }}$ \\
\hline
\end{tabular}

O Frag. 4 parte da questão de pesquisa, porque após apreciar as estratégias mais recorrentes nos seminários as relaciona às unidades retóricas e à mobilização dos conteúdos, requeridos desde a seção de introdução do gênero. Todo o fragmento da coluna Análise de Dados revela a argumentação realizada pelo sujeito escritor de ML-1 acerca do seu objeto investigativo. A estratégia utilizada se evidencia, principalmente, a partir das palavras que contribuem para explicitar a opinião do sujeito escritor sobre as características mais importantes para a efetivação do evento seminário.

As monografias coletadas revelaram que a construção do juízo de valor é perpassada por palavras, que imprimem uma opinião formada a partir da análise de um objeto investigativo, como apreciação, percebemos, parece ser, permitir, ainda que, embora, certamente, muito e interessante. Além disso, a própria linguagem subjetiva revela o juízo construído sobre um objeto, caso das monografias de Ciências Sociais.

Os dados recolhidos deste curso revelaram especificidades de juízo de valor explicadas por meio do Frag. 5, no qual são expostos dois trechos de análise de MCS-3 em que o sujeito escritor do gênero explicita sua subjetividade para com seu objeto de investigação, especialmente, por meio das construções "nós pesquisadores" e "moradores de

\footnotetext{
${ }^{8}$ Argumentação via juízo de valor (AJV).
} 
vila e de cidade como nós". No primeiro trecho, o juízo de valor é sobre a imprevisibilidade de o pesquisador ter descoberto um costume cigano. No segundo trecho de argumentação, o pesquisador opina sobre o novo costume cigano de viver sem a sua característica primária de deslocamento; como se pode observar:

Fragmento 5: Análise de Dados em MCS-3: AJV

\begin{tabular}{|c|c|c|c|}
\hline & $\begin{array}{c}\text { Introdução } \\
\text { (Questão de } \\
\text { pesquisa) }\end{array}$ & Análise de Dados & \\
\hline 1. & 3) “Como se & Interessante observar como em alguns momentos & Argumentação \\
\hline 2. & constroem suas & pesquisadores nos deparamos com certas informaç̃es que nem & (juízo de \\
\hline 3. & relações sociais & sequer foram vistas ou perguntadas ao sujeito, como foi o caso das & valor) \\
\hline 4. & diante da & armas portadas. $\quad$ (MCS-3, p. 51) & \\
\hline 5. & fronteira étnica"; & $\underline{\text { Se observarmos bem, tal especificidade tem a sua lógica quando }}$ & $\underline{\text { Argumentação }}$ \\
\hline 6. & 4) "Como vivem, & passamos a adotar a vida em deslocamento como questão de análise: & Guízo de \\
\hline 7. & como & se os ciganos se pensam enquanto seu deslocamento, então, estar & valor) \\
\hline 8. & (re)constroem a & agora num terreno, tendo que viver em casas construídas e não & \\
\hline 9. & sua identidade & transportáveis implica em uma custosa adaptação. Logo, não & \\
\hline 10. & coletiva nos dias & podemos esperar que eles funcionem como moradores de vila e de & \\
\hline 11. & de hoje". & o nós, não-ciganos, estamos acostumados a ser, há muitas & \\
\hline 12. & (MCS-3) & MCS-3 (p. 58) & \\
\hline
\end{tabular}

No Frag. 5, ambos os trechos se relacionam à terceira e à quarta questão de pesquisa, ao argumentarem sobre os atuais costumes de ciganos. As argumentações postas evidenciam a linguagem subjetiva empregada em Ciências Sociais. A utilização dessa linguagem aponta para uma maneira de mostrar a indissociação entre o fazer-científico nesta área e, grosso modo, a própria sociabilidade do pesquisador. Em síntese, o juízo de valor constrói posicionamentos críticos nestas monografias.

\section{O contínuo dos processos de retextualização interna}

A inter-relação entre as estratégias realizadoras dos processos de adaptação, reformulação e argumentação ocorre no contínuo entre questões de pesquisa e análise de dados, sendo utilizadas para descrever, relacionar, comparar, interpretar e se posicionar criticamente ante um objeto investigativo, segundo delineia o Frag. 6:

Fragmento 6: Análise de Dados ML-2: RA; RR, AJV e APAR

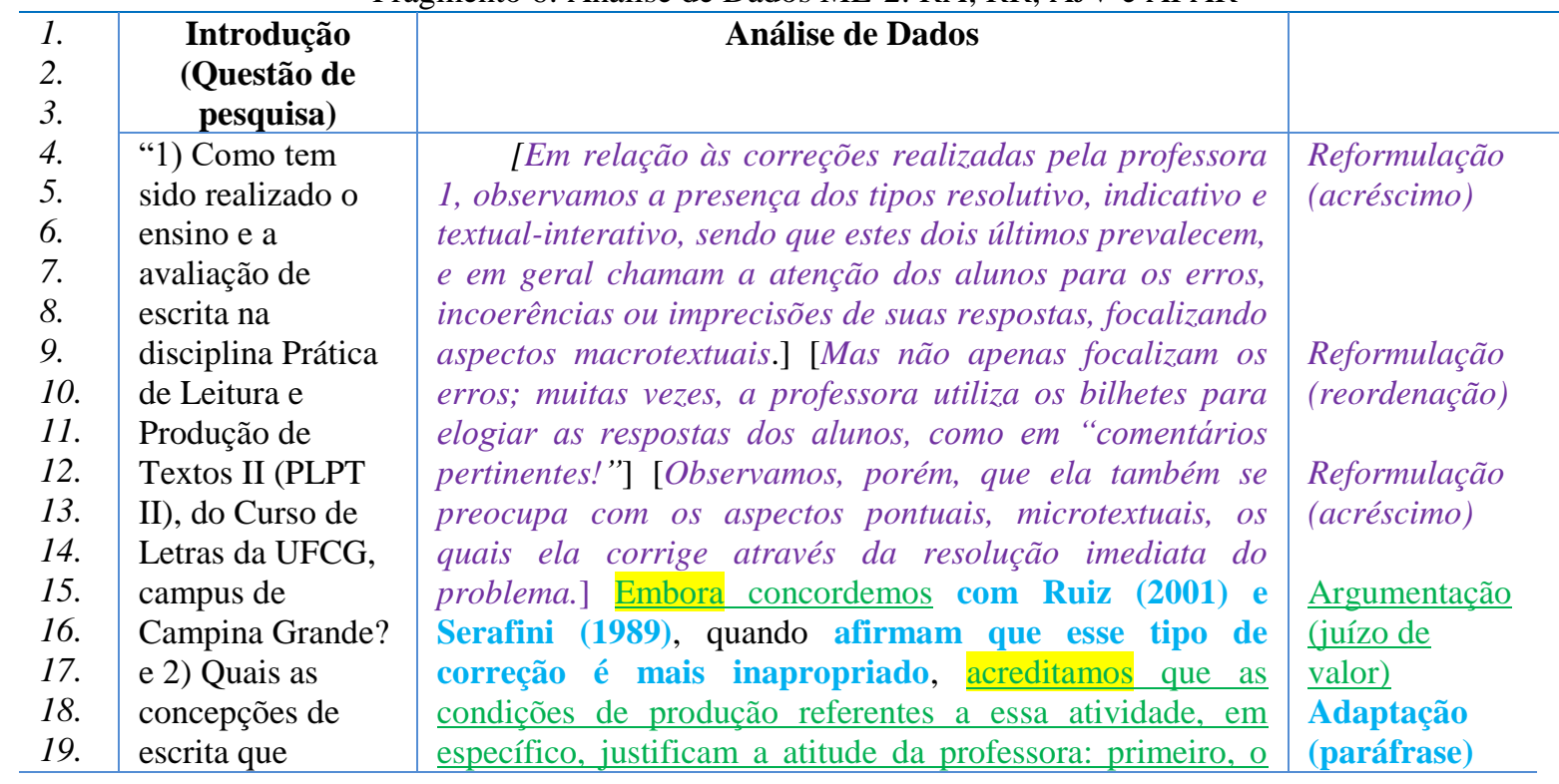




\begin{tabular}{|c|c|c|}
\hline $\begin{array}{l}20 . \\
21 . \\
22 . \\
23 .\end{array}$ & $\begin{array}{l}\text { possuem as } \\
\text { professoras que } \\
\text { lecionam essa } \\
\text { disciplina?." (ML- } \\
\text { 2) }\end{array}$ & 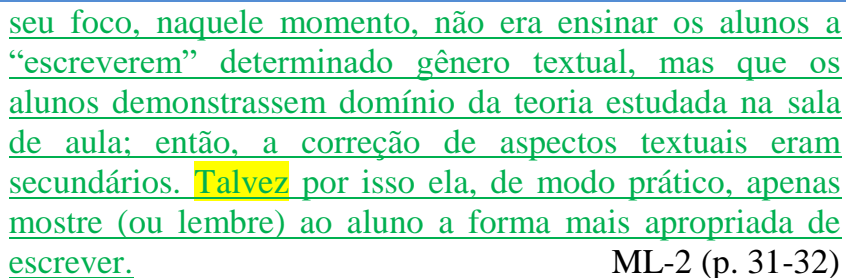 \\
\hline
\end{tabular}

O parágrafo exposto neste fragmento é produzido no penúltimo tópico de análise de ML-2, Práticas de avaliação. O parágrafo se inicia com a estratégia de acréscimo, indo de "Em relação" (linha 1) a "aspectos macrotextuais" (linha 6), em que se descreve o modo de o sujeito de pesquisa (a professora 1) avaliar textos dos alunos de PLTP II, contribuindo para que as questões de pesquisa apresentadas sejam respondidas.

A partir da referida estratégia, desencadeia-se uma reordenação acerca dos erros que a professora corrige, de modo que são apresentados no fim do primeiro período do parágrafo e retomados no início do período seguinte "Mas não apenas focalizam os erros". Na sequência, outro acréscimo descreve a atitude da professora 1 de se preocupar também com os aspectos microtextuais dos textos dos alunos de PLPT-II (linhas 9-12).

Através das descrições no processo de reformulação, o sujeito escritor da monografia julga a atitude da professora 1 a partir da observação e descrição posta do contexto de pesquisa e da relação com os pressupostos teóricos parafraseados. A inserção da paráfrase "Ruiz (2001) e Serafini (1989) (...) afirmam que esse tipo de correção é mais inapropriado" (linhas 13-14) demonstra o fundamento teórico do juízo de valor emitido.

O juízo atribuído se inicia com "Embora concordemos" (linha 12) e termina com o argumento que ratifica a opinião do sujeito escritor de ML-2 sobre as atitudes da professora 1 "Talvez por isso ela, de modo prático, apenas mostre (ou lembre) ao aluno a forma mais apropriada de escrever" (linhas 21-23). A referida estratégia é evidenciada pela concessão sinalizada por embora, pela apreciação encabeçada por acreditamos e pela opinião aferida por talvez.

Conforme se verifica, os processos realizáveis em estratégias de retextualização acontecem em um contínuo textual-discursivo que contribui para a produção de análise em monografias. O contínuo observado parte do fato de que as monografias coletadas validam o caráter científico esperado para o gênero, através de pressupostos teóricos que as fundamentaram, da maneira como o Frag. 7 também demonstra:

Fragmento 7: Análise de Dados ML-1: RA; ACIT e AJV

\begin{tabular}{|c|c|c|c|}
\hline & $\begin{array}{c}\text { Introdução } \\
\text { (Questão de } \\
\text { pesquisa) }\end{array}$ & Análise de Dados & \\
\hline $\begin{array}{l}1 . \\
2 . \\
3 . \\
4 . \\
5 . \\
6 . \\
7 . \\
8 . \\
9 . \\
10 . \\
11 .\end{array}$ & $\begin{array}{l}\text { "Qual a } \\
\text { interferência das } \\
\text { unidades retóricas } \\
\text { na prática de } \\
\text { seminário para a } \\
\text { mobilização dos } \\
\text { conteúdos?" } \\
\text { ML-1 }\end{array}$ & $\begin{array}{l}\text { Baseados nesse estudo, podemos acrescentar à ideia } \\
\text { apresentada por Dolz, Schneuwly (et. al. op cit., p. 220- } \\
\text { 221), de que "a exposição deverá ser ordenada em partes } \\
\text { e subpartes, que permitam distinguir as fases sucessivas } \\
\text { de sua construção interna", a noção de didatização dos } \\
\text { conhecimentos. } \\
\text { Trazer tais estratégias, apenas, não garante a qualidade } \\
\text { do evento e a apreensão do conteúdo por parte da audiência, } \\
\text { sendo necessário e relevante uma proposta de ação que } \\
\text { promova a interação entre os conteúdos e a plateia, e destes } \\
\text { entre si, numa construção efetiva do conhecimento. } \\
\text { ML-1 (p. 56) }\end{array}$ & $\begin{array}{l}\text { Reformulação } \\
\text { (acréscimo) } \\
\text { Adaptação } \\
\text { (citação) }\end{array}$ \\
\hline
\end{tabular}

O Frag. 7 retoma o primeiro ora apresentado (no tópico anterior deste artigo), em que se analisa a citação como estratégia de retextualização. Na ocasião, discute-se a referência 
direta a Dolz e Schneuwly adaptada à ML-1. A citação posta se insere na estratégia de acréscimo, ao introduzir a característica de seminários acadêmicos para a didatização de conhecimentos.

Além disso, esta relação entre uma estratégia do processo de reformulação e uma do processo de adaptação coaduna no juízo de valor (linhas 7-11) em que o sujeito de ML-1 defende uma nova proposta de seminário "que promova a interação entre os conteúdos e a plateia, e destes entre si, numa construção efetiva do conhecimento". O capítulo de análise de ML-1 é finalizado com estes parágrafos do Fragmento 7, como uma resposta para a questão de pesquisa posta, revelando a apropriação de dados analisados a partir de teorizações fundamentadas, e contribuindo com um caráter de novidade com os estudos lidos de Dolz e Schneuwly (2004). O fragmento apresenta a necessária relação entre teorias lidas e apreciação do objeto de pesquisa, através de estratégias como, por exemplo, citação e juízo de valor. Com isso, as estratégias investigadas contribuíram para a validação da escrita do gênero em estudo, juntamente com o fazer científico esperado para monografias.

Deste modo, os fragmentos 6 e 7 comprovaram que as estratégias dos processos de adaptação, reformulação e argumentação ocorrem em um contínuo de retextualização. No contínuo, não há uma hierarquia para a disposição dos processos, mas uma inter-relação entre eles para que a seção de análise produza conhecimento e alcance o fazer científico do gênero. A partir destas constatações, contabiliza-se através da Fig. 2 a frequência com que estes processos perpassam a análise produzida nas monografias estudadas:

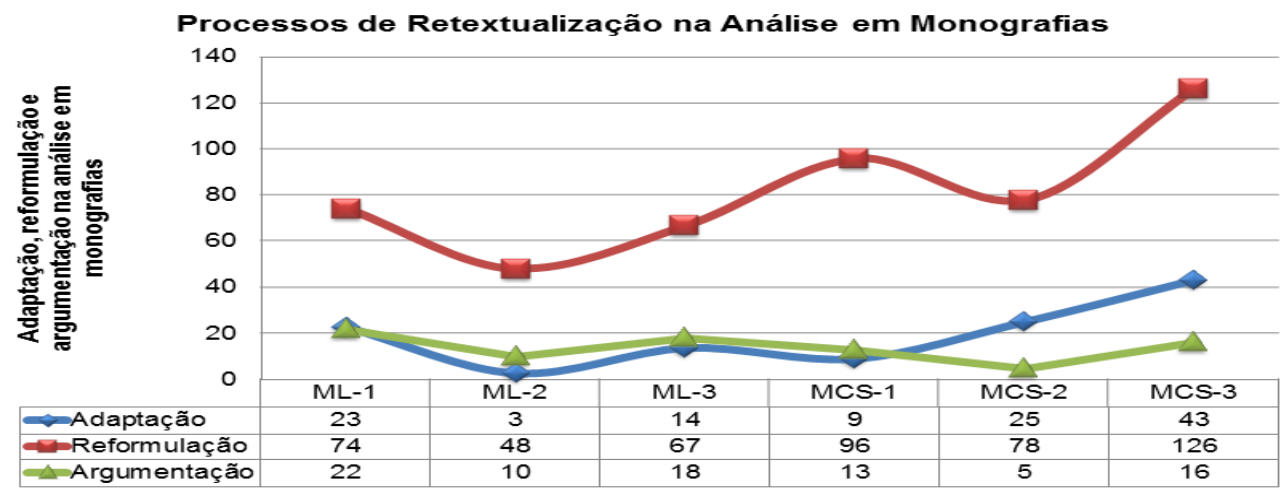

Figura 2: Processos de Retextualização na Análise em Monografias Fonte: Elaborado pelas autoras a partir dos dados coletados

Comparando a ocorrência dos três processos em cada análise das seis monografias investigadas, o gráfico exposto na Fig. 2 confirma que, em primeiro lugar, o processo reformulação, realizável pelas estratégias acréscimo e reordenação, foi o mais recorrente. Em relação aos demais processos, registram-se um total de 63\% de reformulações em ML-1; 79\% em ML-2; 68\% em ML-3; 81\% em MCS-1, 72\% em MCS-2 e 68\% em MCS-3. Logo, foram $69 \%$ de reformulações nas monografias de Letras e $74 \%$ nas de Ciências Sociais, revelando que ambos os cursos se valem com maior frequência de estratégias descritivas para analisar o objeto investigativo.

Em segundo lugar, as adaptações ocorreram mais nas monografias de Ciências Sociais, com 18\%, do que nas de Letras, com 13\%. A diferença de 5\% confirma que as monografias de Ciências Sociais realizam mais citação e paráfrase, possivelmente porque a análise que desenvolve é produzida em capítulos que mesclam teoria e análise, mesmo com os primeiros capítulos do gênero destinados à metodologia e fundamentação teórica. 
O que os números não revelam é o fato de que os $13 \%$ de adaptações se diferenciam também qualitativamente dos $18 \%$, visto que nas monografias de Letras, paráfrases e citações serviram para reafirmar o suporte teórico e para evidenciar a contribuição à teoria. Este motivo indica que tais estratégias têm papel importante na produção da análise do gênero, já que evidenciam a autonomia do seu produtor de aliar as interpretações teóricas à contribuição do trabalho realizado. Por outros motivos, os $18 \%$ foram em parte utilizados como a própria análise no gênero, revelando inadequações quanto à funcionalidade de paráfrase e citação.

Em terceiro lugar, o processo de argumentação predominou nas monografias de Letras $(18 \%, 16 \%$ e 18\%, respectivamente) em detrimento às de Ciências Sociais $(11 \%, 5 \%$ e $9 \%$ ). No total, foram $18 \%$ contra $8 \%$ de argumentações nas análises de um e do outro curso, comprovando a existência de estratégias mais interpretativas em Letras e mais descritivas em Ciências Sociais.

No geral, os índices confirmam que o processo de reformulação foi o mais utilizado, com $72 \%$, em relação aos $15 \%$ de adaptação e os $13 \%$ de argumentação. Apesar de a argumentação ter sido menos utilizada, é o processo que melhor caracteriza a seção de análise de dados de monografias, porque evidencia a produção de conhecimento e o posicionamento crítico esperado no gênero, segundo comprovamos em Souza (2014).

Diante dos resultados, ao menos dois motivos podem ser elencados para explicar a menor recorrência do processo de argumentação, via juízo de valor, em relação aos outros dois processos. Por um lado, o posicionamento crítico esperado decorre de apropriação do objeto investigativo e das teorias que fundamentam o gênero monografia, por isso os demais processos se sobressaem, porque descrevem o objeto de investigação e relacionam teoria à análise.

Por outro lado, o baixo índice de argumentação se explica pelo próprio gênero em que ocorre, uma vez que seus sujeitos escritores se encontram em fase iniciante do fazercientífico. Independentemente dos índices de recorrência, comprovamos que a argumentação é usada no decorrer da análise de dados em movimentos cíclicos produzidos pelas estratégias de retextualização, que encadeiam a análise desenvolvida nas monografias em estudo.

\section{Considerações finais}

Na pesquisa divulgada neste artigo, chamou a atenção o fato de a argumentação ter sido o processo menos utilizado, com $13 \%$, contra os $15 \%$ de adaptação e os $72 \%$ de reformulação. Esperava-se a predominância de tal processo na análise das monografias de Letras e de Ciências Sociais, por evidenciar o posicionamento do sujeito produtor do gênero acerca de seu objeto investigativo.

A pouca argumentatividade evidencia que o aluno em fase final de graduação ainda é iniciante na escrita acadêmica ao se posicionar criticamente através de linguagem apreciativa, embora sejam bolsistas egressos do PIBIC e de cursos avaliados como satisfatórios pelo Exame Nacional de Desempenho de Estudantes (na divulgação de 2011, a última que antecedeu o início, em 2012, da pesquisa ora apresentada), o que pressupõe um perfil de sujeitos atuantes em práticas de produção escrita acadêmica não apenas para cumprimento de atividades a partir da sala de aula, mas também de pesquisas de iniciação científica. $O$ pouco posicionamento não desqualifica as monografias produzidas e recolhidas para investigação; contudo, aponta para a necessidade de se trabalhar mais estratégias argumentativas de escrita, de se operar sistematicamente com tarefas específicas em contexto de produção acadêmica na graduação, de se pesquisar mais sobre as particularidades desse contexto de ensino/aprendizagem. 
Por estes motivos, reflete-se sobre o fato de que a análise de dados em monografias deve ir além da descrição e explicação de dados; deve apreciá-los a partir de determinada discussão teórica. Isto implica a contraposição à constatação, ilustração ou à confirmação de teoria. Apreciar é se posicionar enquanto pesquisador que analisa dados para confrontar teorias, concomitantemente à contribuição teórico-metodológica a ser feita, bem como ao contexto social de pertencimento dos dados que, qualquer que seja, é de sua natureza ser problematizado, de maneira que não se restringiria a nenhum enquadramento teórico.

Além dessa reflexão, o gênero monografia é compreendido a partir do seu contexto sociorretórico de ser produzido e reconhecido para o recebimento do título de graduado; analisado a partir da escrita científica em que é validado, ao induzir o sujeito que o escreve no percurso do fazer ciência; e apresentado como decorrente de um contínuo que perpassa a escrita acadêmica, de modo que a sua produção aponta para uma série de outros gêneros previamente produzidos. A sua aprendizagem se dá através de textos que pertençam a eles, o que se contrapõe à transmissão de propriedades formais fixas, dada a sua dinamicidade subjacente. Aprendem-se estratégias textuais para que sejam produzidos. Aprende-se a parafrasear, citar, reformular, argumentar, a elaborar questão, objetivo, a coletar dados, a sistematizá-los, a fazer revisão bibliográfica.

Perante as considerações postas, conclui-se que as estratégias de retextualização validam a escrita monográfica, por serem instrumentos que permitem a um graduando cumprir os processos de adaptar, reformular e argumentar que contribuem para a construção do fazer-científico do gênero estudado.

\section{Referências}

BHATIA, V. K. Worlds of written discourse: a genre-based view. London: Continuum, 2004.

MARCUSCHI, L. A. [2001]. Da fala para a escrita: atividades de retextualização. 10. ed. São Paulo: Cortez, 2010.

MATENCIO, M. de L. M. Atividades de (re)textualização em práticas acadêmicas : um estudo do resumo. Revista Scripta, v. 6, n. 11. Belo Horizonte: PUC Minas. 2002.

. Referenciação e retextualização de textos acadêmicos: um estudo do resumo e da resenha. ANAIS DO III CONGRESSO INTERNACIONAL DA ABRALIN, março de 2003.

O recurso ao discurso do outro na formação inicial: um estudo de textos de alunos de Letras. Intercâmbio (CD-ROM), São Paulo, v. 14, 2004.

SILVA, A. V. Com a palavra, o aluno: processos de retextualização na exposição oral acadêmica. Minas Gerais, 2013. 231f. Tese (Doutorado em Estudos Linguísticos) Universidade Federal de Minas Gerais, Belo Horizonte.

SOUZA, C. R. R. de. Retextualização no gênero monografia. Campina Grande, 2014. 148f. Dissertação (Mestrado em Linguagem e Ensino) - Universidade Federal de Campina Grande, Campina Grande.

SWALES, J. M. Genre analysis: English in academic and researching settings. Cambridge: Cambridge University Press, 1990. 
Press, 2004.

Research genres: exploration and applications. Cambridge: Cambridge University

\section{APÊNDICE: Fontes bibliográficas dos dados coletados}

\begin{tabular}{|l|l|}
\hline \multicolumn{2}{|c|}{ Monografias de Ciências Sociais } \\
\hline MCS-1 & $\begin{array}{l}\text { NUNES, A. M. B. (Re)pecuarização e mudança social da agricultura } \\
\text { familiar no sertão do Pajeú (PE): reconversôes produtivas, reelaborações } \\
\text { discursivas e mudança figuracional no Sitio Santo Izidro (PE). 2011. 61 f. } \\
\text { Monografia. (Curso de Ciências Sociais/ Bacharelado em Ciências Sociais) - } \\
\text { Universidade Federal de Campina Grande - PB. }\end{array}$ \\
\hline MCS-2 & $\begin{array}{l}\text { MENESES, V. F. A constituição de mediadores sociais em projetos de } \\
\text { desenvolvimento: uma reflexão sobre os ADRS no contexto da } \\
\text { (re)pecuarização no cariri paraibano. 2011. 69 f. Monografia. (Curso de } \\
\text { Ciências Sociais/ Bacharelado em Ciências Sociais) - Universidade Federal } \\
\text { de Campina Grande - PB. }\end{array}$ \\
\hline MCS-3 & $\begin{array}{l}\text { CAMILO, A. S. “Andarilhos no meio do mundo”: os diferentes caminhos } \\
\text { trilhados pelos ciganos e o desafio de estar em Patos - PB. 2011. 112 f. } \\
\text { Monografia. (Curso de Ciências Sociais/ Bacharelado em Ciências Sociais) - } \\
\text { Universidade Federal de Campina Grande - PB. }\end{array}$ \\
\hline
\end{tabular}

\begin{tabular}{|c|l|}
\hline \multicolumn{1}{|c|}{ Monografias de Letras } \\
\hline$M L-1$ & $\begin{array}{l}\text { MEIRA, G. H. S. A prática de seminários e as unidades retóricas como } \\
\text { fatores intervenientes. Campina Grande, 2011. 75 f. Monografia. (Curso de } \\
\text { Letras/ Habilitação em Língua Portuguesa) - Universidade Federal de } \\
\text { Campina Grande - PB. }\end{array}$ \\
\hline$M L-2$ & $\begin{array}{l}\text { LIRA, D. M. Práticas de ensino e de avaliação e concepções de escrita em } \\
\text { curso de formação inicial de professor de língua materna. Campina Grande, } \\
\text { 2010. 43 f. Monografia. (Curso de Letras/ Habilitação em Língua Portuguesa) } \\
\text { - Universidade Federal de Campina Grande - PB. }\end{array}$ \\
\hline$M L-3$ & $\begin{array}{l}\text { SILVA, P. S. L. Saberes sobre oralidade mobilizados na formação e na } \\
\text { atuação de professores de língua portuguesa. Campina Grande, 2009. } 67 \mathrm{f} . \\
\text { Monografia. (Curso de Letras/ Habilitação em Língua Portuguesa) - } \\
\text { Universidade Federal de Campina Grande - PB. }\end{array}$ \\
\hline
\end{tabular}

Recebido em: dezembro de 2015.

Aprovado em: março 2016. 